\title{
Occurrence and relevance of Mycoplasma spp. in free-ranging pheasants from northwestern Germany
}

\author{
Luisa Fischer ${ }^{1,4}$ (D) Jennifer Liebing ${ }^{2} \cdot$ Iris Völker $^{3} \cdot$ Liane Baudler $^{1} \cdot$ Friederike Gethöffer $^{2} \cdot$ Ulrich Voigt $^{2}$. \\ Ursula Heffels-Redmann ${ }^{1} \cdot$ Peter Wohlsein ${ }^{3} \cdot$ Ursula Siebert $^{2} \cdot$ Michael Lierz $^{1}$
}

Received: 15 September 2020 / Revised: 3 December 2021 / Accepted: 20 December 2021 / Published online: 4 January 2022

(c) The Author(s) 2022

\begin{abstract}
Since 2008/2009, the population of free-ranging ring-necked pheasants was recorded to decrease all over Germany. Various Mycoplasma (M.) spp. are causing severe respiratory signs in captive game bird species. Furthermore, M. gallisepticum is responsible for massive die-offs in consequence to severe conjunctivitis in house finches in the USA. Therefore, the prevalence of mycoplasmas in free-ranging pheasants was investigated and a potential impact on the population decline of pheasants discussed. Within this study, 150 free-ranging pheasants were sampled via tracheal swabs and tissue samples of the trachea and the periorbital skin, as the latter displayed inflammatory alterations in previous studies. In total, 177 samples were investigated for the presence of mycoplasmas using cultural and molecular biological methods. In 76 birds, necropsy was performed additionally. In total, 73.7\% (51/76) of the examined pheasants had periorbital skin alterations. Furthermore, $64.4 \%(114 / 177)$ of the samples tested positive for mycoplasmas via PCR. Overall, 102/177 samples (57.6\%, 78/105 tracheal swabs, 19/51 skin tissue, 5/21 trachea tissue) tested positive for mycoplasmas via culture. Mycoplasma gallinaceum $(n=50)$, M. pullorum ( $n=45)$, M. glycophilum $(n=43)$, M. iners $(n=11)$, and M. gallinarum $(n=5)$ were frequently isolated. In 45 cases (45.9\%), multiple Mycoplasma spp. were isolated from one sample. All examined samples tested negative for M. gallisepticum. Of 51 skin samples investigated for mycoplasmas, 24 (47.1\%) showed inflammatory skin alterations in histology, and 58.3\% (14/24) of these samples tested positive for Mycoplasma spp. additionally. Overall, there was a significant correlation between inflammatory altered skin samples and the detection of mycoplasmas in periorbital skin samples. Based on the present results, the isolated Mycoplasma spp. may play a role as facultative agents for the observed inflammatory skin alterations. However, additional investigation is needed to confirm this presumption.
\end{abstract}

Keywords Dermatitis $\cdot$ Periorbital inflammation $\cdot$ Facultative pathogens $\cdot$ Mycoplasma $\cdot$ Clinical relevance $\cdot$ Environmental effects

Luisa Fischer

Luisa.Fischer@lanuv.nrw.de

$1 \quad$ Clinic for Birds, Reptiles, Amphibians and Fish, Justus Liebig University, Frankfurter Strasse 114, 35392 Giessen, Germany

2 Institute for Terrestrial and Aquatic Wildlife Research, University of Veterinary Medicine Hanover, Foundation, Bischofsholer Damm 15, 30173 Hanover, Germany

3 Department of Pathology, University of Veterinary Medicine Hannover, Foundation, Buenteweg 17, 30559 Hanover, Germany

4 Wildlife Research Institute, State Agency for Nature, Environment and Consumer Protection North Rhine-Westphalia, Puetzchens Chaussee 226, 53229 Bonn, Germany
Pheasants are ground-breeding birds living mainly in the agricultural landscape of the northwestern part of Germany. As this bird species underlies the German Hunting Law, hunting bag statistics go back over several centuries showing a massive decline in the population since its plateau between 1960 and 1970 (Gehle 2011). Previous studies focused on potential infectious and non-infectious causes for this decline (Curland et al. 2018; Liebing et al. 2020) as well as on potential contributory factors (e.g., pesticides, predation, increasing traffic, changes in agricultural landscape) (Aebischer 1997; Moreby and Southway 1999). Thereby, it was shown that there is rather not a single pathogen but several factors contributing to the decline of pheasants in Germany, e.g., a reduced supply on protein-rich diet (e.g., insects) for pheasant chicks resulting in immunosuppression (Curland et al. 2018; Liebing et al. 2020). 
Upper respiratory tract infections including conjunctivitis and sinusitis are commonly noted in captive bred pheasants (Benčina et al. 2003; Welchman et al. 2002). Serological evidence and cultural findings suggested Mycoplasma gallisepticum (MG) as one of the possible causes of these disease outbreaks (Bradbury et al. 2001; Cookson and Shivaprasad 1994). Histologically, the affected birds exhibited lymphoplasmacytic inflammation of the conjunctiva, sinus, and trachea (Forrester et al. 2011; Ganapathy and Bradbury 1998). Via experimental infections with MG respiratory disease was reproduced in other game bird species (McMartin 1996). Besides MG, other Mycoplasma spp. were commonly isolated in pheasants showing respiratory disease: $M$. gallinaceum (Poveda et al. 1990; Bradbury et al. 2001; Chin and Goshgarian 2001; Welchman et al. 2002), M. gallinarum (Poveda et al. 1990), M. glycophilum (Bradbury et al. 2001; Chin and Goshgarian 2001), M. iners (Bradbury et al. 2001), and M. pullorum (Bradbury et al. 2001; Kempf et al. 1991; Shimizu et al. 1979). However, the clinical relevance of these fast-growing Mycoplasma spp. was unknown as some species were isolated in clinically healthy pheasants, too (Gerlach 1994; Poveda et al. 1990). Except for several studies in captive bred pheasants, investigations in free-ranging populations are rare. However, infectious agents may have been transferred to free-ranging game bird populations by releasing captive bred birds into the wild (De Marco et al. 2002).

Since 1994, massive outbreaks of MG-related conjunctivitis cause high losses in free-ranging populations of house finches (Haemorhous mexicanus) in the USA (Dhondt et al. 2014; Ley et al. 1996). In the following years, MG infections causing severe conjunctivitis were also seen in several other passerine species (Fischer et al. 1997; Hartup et al. 2000; Mikaelian et al. 2001). In some regions, the disease caused population declines in free-ranging house finches of up to 50\% (Hochachka and Dhondt 2000). Affected birds showed conjunctivitis and encrusted eye lids. In histopathology, lymphoplasmacytic inflammation and epithelial hyperplasia around the eyes were seen just like in starlings being infected with M. sturni (Forsyth et al. 1996; Fischer et al. 1997). Phylogenetic studies showed that MG strains from free-ranging house finches may have been evolved from MG strains that were found in poultry by host shift (Delaney et al. 2012; Hochachka et al. 2013).

Investigations in possible causes for the population decline of pheasants in northwestern Germany showed skin alterations around the eyes in numerous birds (Curland et al. 2018). Whether MG or other Mycoplasma spp. are involved in the development of these lesions was investigated within this study.

Samples of respiratory tract and periorbital skin were obtained from free-ranging pheasants caught by live traps, shot during hunting, or found dead in northwestern Germany. Animals caught by live traps and being released again were sampled via tracheal swabs in the field. Dead pheasants were sampled at the hunting bag in the field or within the post-mortem examination. Therefore, tissue samples from trachea and/or skin were obtained, too (Curland et al. 2018). Findings of the post-mortem examination, especially regarding inflammatory skin lesions in the head region, were documented.

All samples were cultured using SP4 liquid and agar media as described by Bradbury (1998b). Each sample was immersed in the SP4 broth and afterwards removed and stored for further investigations. The broth was diluted (tenfold dilution up to $10^{-2}$ ), and an aliquot of $50 \mu \mathrm{l}$ each was transferred onto agar media. Liquid and solid media were incubated at $37{ }^{\circ} \mathrm{C}$ under microaerophilic conditions in a humidified environment for up to 10 days. Broth was examined for color change and agar plates for colony growth daily. In case of mycoplasmal growth, single colony subcultures were performed three times in order to ensure pure cultures, respectively. Each single colony subculture was stored at $-80{ }^{\circ} \mathrm{C}$ until further investigation.

For DNA extraction, swabs were soaked and rubbed in $350 \mu$ phosphate-buffered saline (PBS). Of this liquid, $100 \mu \mathrm{l}$ was used for DNA extraction using the DNeasy ${ }^{\circledR}$ Blood \& Tissue Kit (Qiagen, Hilden, Germany) according to the manufacturer's instructions. For DNA extraction of tissue samples and single colony subcultures, the fluid medium from culturing was centrifuged at $4000 \mathrm{G}$ for $45 \mathrm{~min}$. The remaining pellet was incubated with $180 \mu \mathrm{l}$ lysis buffer (ATL Buffer, Qiagen, Hilden, Germany) and $20 \mu \mathrm{l}$ proteinase K (Qiagen, Hilden, Germany) for $2 \mathrm{~h}$ at $56^{\circ} \mathrm{C}$.

All samples and single colony subcultures were screened via Mycoplasma genus-specific PCR (target: 16S rRNA gene sequence) as described by Van Kuppeveld et al. (1992) modified by Lierz et al. (2007). Furthermore, all samples were examined via MG-specific PCR (Hagen et al. 2004). Of all single colony subcultures, an additional PCR (target: 16S-23S rRNA intergenic transcribed spacer region (ISR) sequence) was performed (Ramírez et al. 2008). The PCR products obtained from both PCRs were sequenced by a commercial DNA sequencing service (LGC Genomics, Berlin, Germany). These sequences were aligned with sequences of Mycoplasma spp. in the NCBI database using BLAST (NCBI, USA) algorithm (Altschul et al. 1990).

Statistical analysis was carried out by using the program GraphPad Prism, version 5.0 for windows (GraphPad Software Inc.). Chi-square tests were used to explore the relation between presence of lesions and the following factors: detection of Mycoplasma spp., location of origin, month of collection, age of the sampled bird, and type of harvest (hunted, trapped, or dead found).

Within this study, 177 samples (105 tracheal swabs, 51 periorbital skin tissue, and 21 trachea tissue) were obtained from 150 pheasants. Ninety-seven birds were caught via live 
trap, 34 birds were shot during the hunting season, and 19 birds were found dead. In total, 94 birds were adult and 56 juvenile. Fifty-eight pheasants were female, 22 male, and in 70 birds, gender was not determined. In total, 77/150 pheasants were examined via post-mortem examination (supplemental material Table 2).

All samples were investigated via culturing and molecular biological methods. In total, 102/177 samples (57.6\%, $78 / 105$ tracheal swabs, $19 / 51$ skin tissue, $5 / 21$ trachea tissue) tested positive for mycoplasmas via culturing. From these samples, several Mycoplasma spp. were isolated and identified: M. gallinaceum $(n=50)$, M. pullorum $(n=45)$, M. glycophilum $(n=43)$, M. iners $(n=11)$, and M. gallinarum $(n=5)$. In 45 cases, multiple of these Mycoplasma spp. were isolated from the same sample. Via genus-specific PCR 114/177 samples tested positive $(64.4 \%, 82 / 105$ tracheal swabs, 21/51 skin tissue, 11/21 trachea tissue). There was a significant correlation between the detection of mycoplasmas (via culture and PCR) and the source of birds (trap, hunting, found dead) ( $r \mathrm{~s} 0.39$ and $0.41(p<0.001)$. However, there was no significant correlation between the detection of Mycoplasma spp. and the location, age, season of sampling, or if birds were healthy or diseased. All examined samples tested negative for MG via species-specific PCR.

Of all juvenile $(n=56)$ and 21/94 adult birds, a pathological examination was performed. In $66.2 \%$ (51/77) of the examined pheasants, periorbital inflammatory alterations were observed in the dermis macroscopically. Mostly, non-purulent perivascular inflammations with different cellular compositions and gradual variable infiltrations of lymphocytes, plasma cells, and macrophages were detected histologically (Fig. 1).

In total, $41.1 \%$ (21/51) skin samples were tested positive for mycoplasmas via culture and/or PCR while 58.9\% (30/51) were tested negative. Of Mycoplasma-positive skin samples, 14/21 (66.7\%) revealed inflammatory alterations in histology while 7/21 (33.3\%) did not. However, while 10/30 (33.3\%) Mycoplasma-negative skin samples showed inflammatory alterations in histology, 20/30 (66.7\%) did not (supplemental material table 1). Therefore, a significant correlation between the occurrence of inflammatory skin alterations and the presence of mycoplasmas was shown (chi-square test).

A decline of the population of free-ranging pheasants of northwestern Germany was observed since 2008/2009. In previous studies, no indication of a specific pathogen as a sole cause for this decline was identified; instead, several potential pathogens were detected (Curland et al. 2018). Within the study of Curland et al. (2018), almost half of the examined birds (49.7\%) displayed inflammatory alterations of the periocular dermis. However, the number of birds examined for mycoplasmas was quite low $(n=5)$, so the focus of this study was to concentrate on the investigation of the periorbital skin alterations and the association with mycoplasmas as possible cause.

The investigated birds were mainly obtained via trapping and hunting, but also dead found birds were sampled. Juvenile birds were mostly caught via live trap, while one-third of the adult pheasants were shot by hunting. Therefore, all juvenile birds $(n=56)$ were investigated via post-mortem
Fig. 1 Pheasant, periocular skin, perivascular predominantly lymphocytic infiltration of the dermis (arrows), HE, bar $=100 \mu \mathrm{m}$

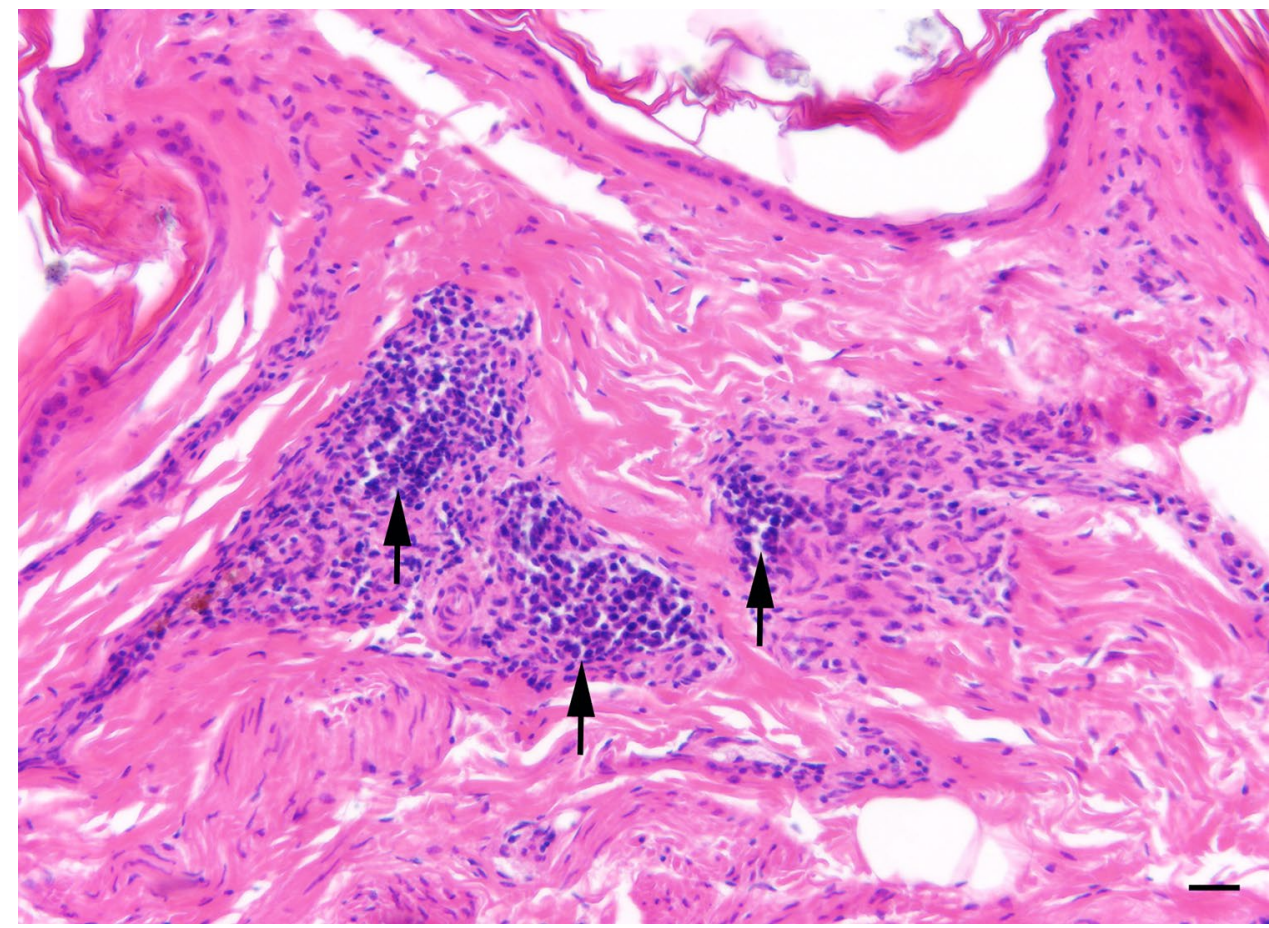


examination, while this was possible in only $21 / 94$ adult pheasants due to further use of the hunting bags. However, investigation for mycoplasmas was technically possible in all 150 pheasants.

Via culture, $57.6 \%$ of the samples tested positive for mycoplasmal growth while $64.4 \%$ tested positive via molecular biological methods. These differences in sensitivity are well known and may be related to the number of mycoplasmas in the sampled material and the viability of the organism (Bradbury 1998b). In this study, tissue samples and swabs were transported cooled down in cultural medium for 12 to $24 \mathrm{~h}$ so that even slowly growing Mycoplasma spp. are cultivatable afterwards (Zain and Bradbury 1996). However, transport of the samples may have led to a decreased viability of mycoplasmas. Furthermore, contamination with other microbial agents occurred in some cases.

In total, $66.7 \%$ of the pheasants tested positive for mycoplasmas. Mycoplasma gallinaceum, M. gallinarum, M. glycophilum, M. iners, and M. pullorum were regularly isolated. These species were also isolated from the respiratory tract and/or the eyes of captive, healthy, and diseased pheasants (Bradbury et al. 2001; Chin and Goshgarian 2001; Kempf et al. 1991; Poveda et al. 1990; Shimizu et al. 1979; Welchman et al. 2002). However, MG was not detected in this study. As MG induces lymphoplasmacytic inflammation of the conjunctiva in certain host species, other Mycoplasma spp. may represent facultative pathogens causing similar alterations when causing disease. Mycoplasma sturni is responsible for severe conjunctivitis in various bird species (Forsyth et al. 1996; Frasca et al. 1997; Ley et al. 1998; Wellehan et al. 2001), but was also found in healthy corvids (Ziegler et al. 2017). Furthermore, corvids suffering from stressful conditions showed a higher prevalence (31\%) than healthy individuals (7\%). Therefore, as M. sturni in corvids, the Mycoplasma spp. isolated in the periorbital skin of pheasants may play a role as facultative pathogens in this bird species.

In the present study, inflammatory alterations in the periorbital region were found more often $(73.7 \%)$ as in prior studies on pheasants in northwestern Germany (49.7\%) (Curland et al. 2018). Furthermore, there was a significant correlation between the detection of mycoplasmas in the periorbital skin and the occurrence of inflammatory skin alterations around the eyes. As the alterations displayed a lymphoplasmacytic character, isolated Mycoplasma spp. are possibly involved in the genesis of the observed alterations (Gerlach 1994). However, to demonstrate the role of the detected mycoplasmas in the inflamed tissue, further investigations would be necessary (e.g., immunofluorescence (Bradbury 1998a)). Differential causes for periorbital skin alterations include ectoparasites, allergic reactions, and/or irritation by toxic agents (e.g., pesticides (Pass 1989)) or immunosuppression associated with secondary bacterial infections (Huff et al. 2013; Thachil et al. 2014). Furthermore, a contribution of infectious bronchitis virus (IBV) in the formation of skin alterations in the head region was discussed in prior studies (Liebing et al. 2020). Furthermore, the time being caught in the live traps may lead to injuries especially at the bird's head due to escape reflex. However, as birds of all groups (caught in live trap, dead found, and shot) showed similar periorbital skin alterations, this possibility seems unlikely, especially as traumatic injuries would have resulted in different macroscopic and microscopic findings. In total, none of the dead found pheasants died due to the detected periorbital skin alterations as seen in house finches in the USA (Nolan et al. 1998).

As a higher percentage of the investigated chicks showed alterations associated with the detection of mycoplasmas in the periorbital skin (53.3\%) compared to the investigated adult pheasants (13.8\%), an age-dependency seems possible. As an immunosuppression of pheasant chicks due to a deficient protein uptake via nourishment was confirmed recently (Liebing et al. 2020), a higher percentage of Mycoplasmapositive chicks showing periorbital skin alteration would support the theory of an involvement of the isolated Mycoplasma spp. as facultative pathogens.

In conclusion, mycoplasmas may play a role as possible cause of the observed periorbital alterations, as they may represent facultative pathogens in free-ranging pheasants. However, there are no indications for the transmission of MG from captive bred pheasants to the free-ranging population. As the habitat of free-ranging pheasants is closely connected with human activities and their effects (habitat loss, decreased food availability, pesticides), they are steadily exposed to multiple stressors. The combination of these endo- and exogenous infectious and noninfectious factors may lead to general weakening with immunosuppression which may contribute to infectious diseases possibly caused by facultative pathogens like mycoplasmas (Fairbrother et al. 2004).

Supplementary information The online version contains supplementary material available at https://doi.org/10.1007/s10344-021-01557-4.

Acknowledgements We thank the Hunters' Association of Lower Saxony, North Rhine-Westphalia, and Schleswig-Holstein for their support of the study. Furthermore, special thanks to Nele Curland, Antoinette Huhn, and Ralf Doerr for their scientific and technical assistance.

Funding Open Access funding enabled and organized by Projekt DEAL. The Lower Saxony Ministry of Food, Agriculture, and Consumer Protection; the State Agency for Nature, Environment, and Consumer Protection of North Rhine-Westphalia; and the Ministry of Energy, Agriculture, the Environment, and Rural Areas of SchleswigHolstein provided financial support to the study. 


\section{Declarations}

Conflict of interest The authors declare no competing interests.

Open Access This article is licensed under a Creative Commons Attribution 4.0 International License, which permits use, sharing, adaptation, distribution and reproduction in any medium or format, as long as you give appropriate credit to the original author(s) and the source, provide a link to the Creative Commons licence, and indicate if changes were made. The images or other third party material in this article are included in the article's Creative Commons licence, unless indicated otherwise in a credit line to the material. If material is not included in the article's Creative Commons licence and your intended use is not permitted by statutory regulation or exceeds the permitted use, you will need to obtain permission directly from the copyright holder. To view a copy of this licence, visit http://creativecommons.org/licenses/by/4.0/.

\section{References}

Aebischer NJ (1997) Effects of cropping practices on declining farmland birds during the breeding season. Brighton Crop Protection Conference. Conf Proc 1-3:915-922

Altschul SF, Gish W, Miller W, Myers EW, Lipman DJ (1990) Basic Local Alignment Search Tool. J Mol Biol 215

Benčina D, Mrzel I, Rojs OZ, Bidovec A, Dovč A (2003) Characterisation of Mycoplasma gallisepticum strains involved in respiratory disease in pheasants and peafowl. Vet Rec 152:230-234

Bradbury JM (1998a) Identification of mycoplasmas by immunofluorescence. In: Miles R, Nicholas RAJ (eds) Methods in molecular biology, vol 1. Mycoplasma Protocols. Humana Press, Totowa, New Jersey, pp 119-125

Bradbury JM (1998b) Recovery of mycoplasmas from birds. In: Miles R, Nicholas RAJ (eds) Methods of molecular biology, vol 1. Mycoplasma protocols. Humana Press, Totowa, New Jersey, pp $45-51$

Bradbury JM, Yavari CA, Dare CM (2001) Mycoplasmas and respiratory disease in pheasants and partridges. Avian Pathol 30:391-396

Chin RP, Goshgarian M (2001) Infraorbital sinusitis associated with Pasteurella multocida in pen-raised ring-necked pheasants. Avian Dis 45:540-543

Cookson KC, Shivaprasad HL (1994) Mycoplasma gallisepticum infection in chukar partridges, pheasants, and peafowl. Avian Dis 38:914-921

Curland N, Gethöffer F, van Neer A, Ziegler L, Heffels-Redmann U, Lierz M, Baumgärtner W, Wohlsein P, Völker I, Lapp S, Bello A, Pfankuche VM, Braune S, Runge M, Moss A, Rautenschlein S, Jung A, Teske L, Strube C, Schulz J, Bodewes R, Osterhaus ADME, Siebert U (2018) Investigation into diseases in free-ranging ring-necked pheasants (Phasianus colchicus) in northwestern Germany during population decline with special reference to infectious pathogens. Eur J Wildl Res 64:12

De Marco MA, Delogu M, Catelli E, Terregino C, Guberti V (2002) Seroprevalences against Mycoplasma gallisepticum and Mycoplasma synoviae detected in free-living and reared pheasants in Emilia Romagna region. Large Anim Rev 8:105-106

Delaney NF, Balenger S, Bonneaud C, Marx CJ, Hill GE, FergusonNoel N, Tsai P, Rodrigo A, Edwards SV (2012) Ultrafast evolution and loss of CRISPRs following a host shift in a novel wildlife pathogen, Mycoplasma gallisepticum. PLoS Genet 8:e1002511
Dhondt AA, DeCoste JC, Ley DH, Hochachka WM (2014) Diverse wild bird host range of Mycoplasma gallisepticum in eastern North America PloS One 9:e103553

Fairbrother A, Smits J, Grasman KA (2004) Avian Immunotoxicology J Toxicol Environ Health, Part B 7:105-137

Fischer JR, Stallknecht DE, Luttrell P, Dhont AA, Converse KA (1997) Mycoplasmal conjunctivitis in wild songbirds: the spread of a new contagious disease in a mobile host population. Emerg Infect Dis 3(1):69

Forrester CA, Bradbury JM, Dare CM, Domangue RJ, Windsor H, Tasker JB, Mockett APA (2011) Mycoplasma gallisepticum in pheasants and the efficacy of tylvalosin to treat the disease. Avian Pathol 40:581-586

Forsyth MH, Tully JG, Gorton TS, Hinckley L, Frasca Jr S, Van Kruiningen HJ, Geary SJ (1996) Mycoplasma sturni sp. nov., from the conjunctiva of a European starling (Sturnus vulgaris) Int J Syst Evol Microbiol 46:716-719

Frasca S Jr, Hinckley L, Forsyth MH, Gorton TS, Geary SJ, Van Kruiningen HJ (1997) Mycoplasmal conjunctivitis in a European starling. J Wildl Dis 33:336-339

Ganapathy K, Bradbury JM (1998) Pathogenicity of Mycoplasma gallisepticum and Mycoplasma imitans in red-legged partridges. Alectoris rufa Avian Pathol 27:455-463

Gehle T (2011) Retrospektive zum Rückgang des Fasans. Schriftenreihe desLandesjagdverbandes Bayern 18:13-24

Gerlach H (1994) Mycoplasma and Rickettsia. In: Ritchie BW, Harrison GJ, Harrison LR (eds)Avian Medicine. Principles and Applications. Wingers Publishing, Inc., LakeWorth 1053-1060

Hagen N, Lierz M, Hafez HM (2004) Das Vorkommen von Mykoplasmen bei Storchnestlingen in Brandenburg und Sachsen-Anhalt. In: 14. DVG- Tagung über Vogelkrankheiten, München, Germany

Hartup BK, Kollias GV, Ley DH (2000) Mycoplasmal conjunctivitis in songbirds from New York. J Wildl Dis 36(2):257-264

Hochachka WM, Dhondt AA (2000) Density-dependent decline of host abundance resulting from a new infectious disease. Proc Nat Acad Scien 97:5303-5306

Hochachka WM, Dhondt AA, Dobson A, Hawley DM, Ley DH, Lovette IJ (2013) Multiple host transfers, but only one successful lineage in a continent-spanning emergent pathogen. Proc R Soc Lond B Biol Sci 280:20131068

Huff GR, Huff WE, Rath NC (2013) Dexamethasone immunosuppression resulting in turkey clostridial dermatitis: a retrospective analysis of seven studies, 1998-2009. Avian Dis 57:730-736

Kempf I, Gesbert F, Guinebert E, Guittet M, Bennejean G (1991) Isolation and characterization of Mycoplasma from pheasant breeders (Mycoplasma pullorum) Recueil de Medecine Veterinaire (France) 167:1133-1139

Ley DH, Berkhoff JE, McLaren JM (1996) Mycoplasma gallisepticum isolated from house finches (Carpodacus mexicanus) with conjunctivitis. Avian Dis 40:480-483

Ley DH, Geary SJ, Berkhoff JE, McLaren JM, Levisohn S (1998) Mycoplasma sturni from blue jays and northern mockingbirds with conjunctivitis in Florida. J Wildl Dis 34:403-406

Lierz M, Hagen N, Harcourt-Brown N, Hernandez-Divers SJ, Lüschow D, Hafez HM (2007) Prevalence of mycoplasmas in eggs from birds of prey using culture and a genus-specific mycoplasma polymerase chain reaction. Avian Pathol 36:145-150

Liebing J, Völker I, Curland N, Wohlsein P, Baumgärtner W, Braune S, Runge M, Moss A, Rautenschlein S, Jung A, Ryll M, Raue K, Strube C, Schulz J, Heffels-Redmann U, Fischer L, Gethöffer F, Voigt U, Lierz M, Siebert U (2020) Health status of free-ranging ring-necked pheasant chicks (Phasianus colchicus) in NorthWestern Germany. PLoS One 15(6):e0234044 
McMartin DA, DaMassa AJ, McKeen WD, Read D, Daft B, Lam KM (1996) Experimental reproduction of Mycoplasma gallisepticum disease in chukar partridges (Alectoris graeca). Avian Dis 40:408-416

Mikaelian I, Ley DH, Claveau R, Lemieux M, Bérubé JP (2001) Mycoplasmosis in evening and pine grosbeaks with conjunctivitis in Quebec. J Wildl Dis 37(4):826-830

Moreby SJ, Southway SE (1999) Influence of autumn applied herbicides on summer and autumn food available to birds in winter wheat fields in southern England. Agr Ecosyst Environ 72(3):285-297

Nolan PM, Hill GE, Stoehr AM (1998) Sex, size, and plumage redness predict house finch survival in an epidemic. Proceedings of the Royal Society of London b: Biological Sciences 265:961-965

Pass DA (1989) The pathology of the avian integument: a review. Avian Pathol 18:1-72

Poveda JB, Carranza J, Miranda A, Garrido A, Hermoso M, Fernandez A, Domenech J (1990) An epizootiological study of avian mycoplasmas in southern Spain. Avian Pathol 19:627-633

Ramírez AS, Naylor CJ, Pitcher DG, Bradbury JM (2008) High interspecies and low intra-species variation in $16 \mathrm{~S}-23 \mathrm{~S}$ rDNA spacer sequences of pathogenic avian mycoplasmas offers potential use as a diagnostic tool. Vet Microbiol 128:279-287

Shimizu T, Numano K, Uchida K (1979) Isolation and identification of mycoplasmas from various birds: an ecological study. Jap J Vet Sci 28:538-546
Thachil AJ, Shaw DP, Nagaraja KV (2014) Effects of dexamethasone immunosuppression on turkey clostridial dermatitis. Avian Dis 58:433-436

Van Kuppeveld FJ, van der Logt JT, Angulo AF, van Zoest MJ, Quint WG, Niesters HG, Galama JM, Melchers WJ (1992) Genus-and species-specific identification of mycoplasmas by $16 \mathrm{~S}$ rRNA amplification. Appl Environ Microbiol 58:2606-2615

Welchman DdB, Bradbury JM, Cavanagh D, Aebischer NJ (2002) Infectious agents associated with respiratory disease in pheasants. Vet Rec 150:658-664

Wellehan JFX, Calsamiglia M, Ley DH, Zens MS, Amonsin A, Kapur V (2001) Mycoplasmosis in captive crows and robins from Minnesota. J Wildl Dis 37:547-555

Zain ZM, Bradbury JM (1996) Optimising the conditions for isolation of Mycoplasma gallisepticum collected on applicator swabs. Vet Microbiol 49:45-57

Ziegler L, Möller Palau-Ribes F, Schmidt L, Lierz M (2017) Occurrence and relevance of Mycoplasma sturni in free-ranging corvids in Germany. J Wildl Dis 53:228-234

Publisher's Note Springer Nature remains neutral with regard to jurisdictional claims in published maps and institutional affiliations. 